\title{
The Research and Application of Bright Spot Quantitative Interpretation in Deepwater Exploration
}

\author{
Yi He, Jitian Zhu, Yingzhao Zhang, Aiqun Liu, Guangchao Pan \\ Zhanjiang Branch of China National Offshore Oil Corporation Ltd., Zhanjiang, China \\ Email: heyiufo@hotmail.com
}

How to cite this paper: He, Y., Zhu, J.T., Zhang, Y.Z., Liu, A.Q. and Pan, G.C. (2017) The Research and Application of Bright Spot Quantitative Interpretation in Deepwater Exploration. Open Journal of Geology, 7, 588-601.

https://doi.org/10.4236/ojg.2017.74040

Received: March 3, 2017

Accepted: April 27, 2017

Published: April 30, 2017

Copyright ( 92017 by authors and Scientific Research Publishing Inc. This work is licensed under the Creative Commons Attribution International License (CC BY 4.0).

http://creativecommons.org/licenses/by/4.0/

\begin{abstract}
Prospectors usually recognize the event with strong amplitude in seismic sections as bright spots. However, such a simple and rough method can't distinguish whether these bright spots are related to favorable gas layer or water layer directly. In this paper, for the high correlation between reservoir gascontent and amplitude anomaly in research area, based on rock physical analysis of the wells drilled, using forward modeling technique respectively simulates and analyzes the seismic amplitude of gas layer and water layer. Then, combining the simulation result with corresponding statistics amplitude obtains the numerical relationship between each layer amplitude. At last, using the display technique directly recognizes the bright spots of gas layer in seismic profile and gets rid of those false bright spots caused by water layer, which improved the robustness in the bright spots interpretation and provided reliable basis for reducing exploration risks. Moreover, applying the method to the target zone, we obtain huge success.
\end{abstract}

\section{Keywords}

Bright Spot, Wedge Model, Tuning Thickness, Rock Physical Analysis, Amplitude Quantitative Interpretation

\section{Introduction}

Bright Spot Technology [1] [2] is a method used to detect oil and gas accumulated in traps based on real amplitude, which became an important or indispensable means in oil-gas exploration with good results in practical application [3] [4]. This technology is based on the change of seismic wave amplitude versus hydrocarbon in reservoir. Usually when searching the favorable target with bright spot, we mostly used the energy strength of seismic amplitude to distin- 
guish the bright spot, and eventually achieved the target evaluation. This method to determine whether the stratigraphic is a favorable target is simple and rough, which can't actually judge whether the stratigraphic really contains gas on the basis of the strong amplitude from seismic profile. According to bright spot identification, the upper and lower groups of strata are characterized by strong amplitude and continuous reflection in the central canyon target area of the deep water area of the South China Sea. Based on that, the target in two strata has been evaluated and drilled. The drilling result indicated that the lower bright spot is thick sandstone that was full of high-yield gas. It was found that both gas layer and water layer drilled the well L1 and well L2 show bright spot features in seismic profile with horizontal contrast (Figure 1).

The practice has proved that not all the bright spots are the reflection of oil and gas reservoirs and all the oil and gas reservoirs do not necessarily show the bright spot characteristic. This bright spot feature in seismic profile is the expression of not only oil and gas, but also some special geological bodies like water layer. In 1975 [5], according to the success or failure experience in Bright Spot technology, Royal Dutch Shell considered most bright spots have been not resulted in by the hydrocarbon reservoirs which have commercial value, and warned the industry that there have been some traps in bright spots in time. Bright Spot technology has become one of the key technologies in oil and gas exploration, which has been used to discover lots of large and medium oil-gas fields successfully. With the deepening of exploration more and more cases of failure in Bright Spot technology have come, whose drawback of multi-solution has been exposed gradually [6] [7] [8] [9]. By analyzing the reason of the failure, it is attributed to the multi-solutions of the geophysics that is the equivalent of petrophysical properties. Therefore, in order to better serve the exploration, Bright Spot technology also needs to keep pace with the times. According to the

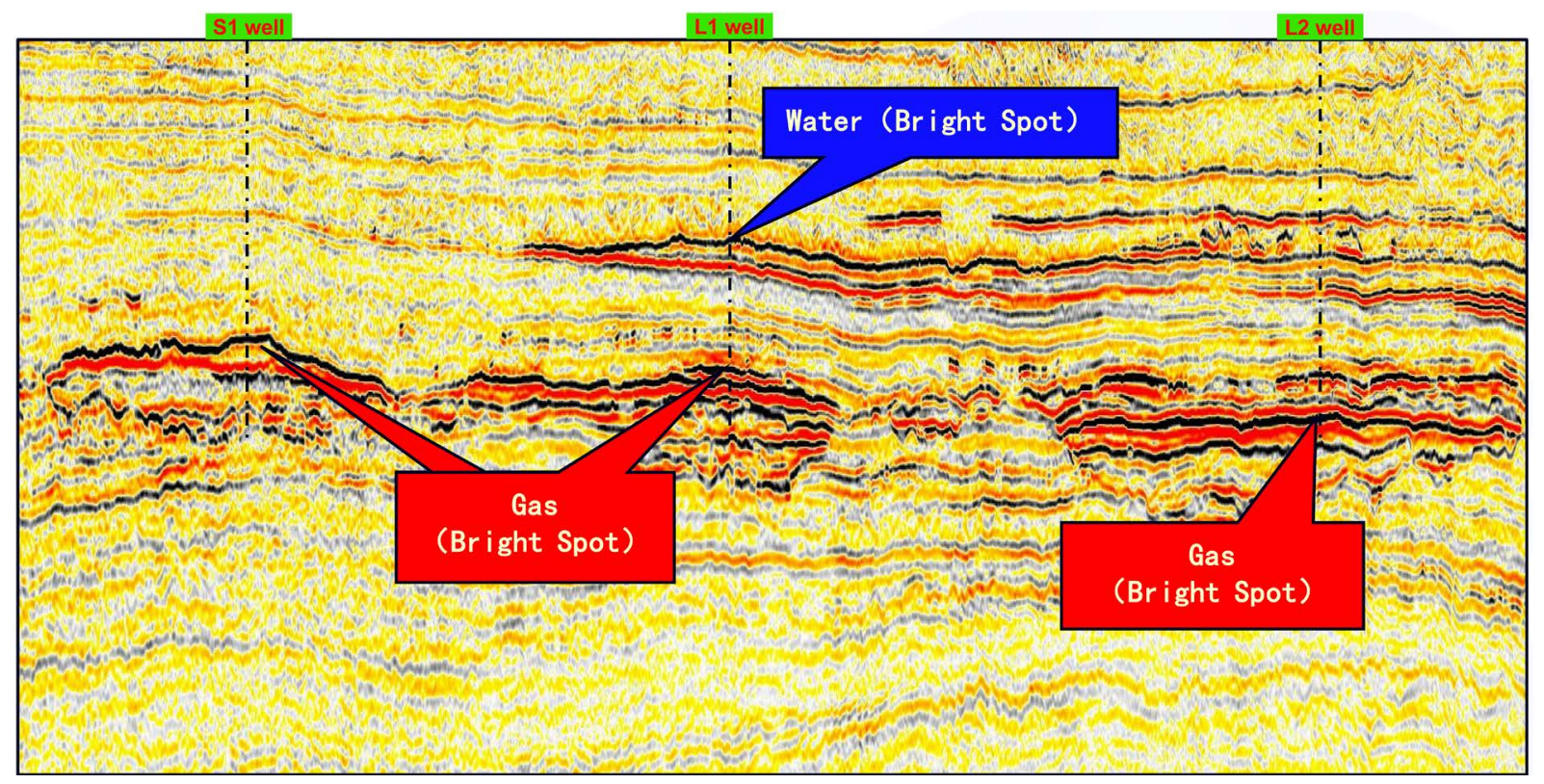

Figure 1. The true bright spots in conventional seismic section of three wells drilled. 
change of oil and gas exploration environment and in order to meet the new demand, it is necessary to further study and improve the applicability of Bright Spot technology.

By analyzing the petrophysical data of the wells drilled in the study area, it is found that there is a great difference between the elastic parameters of the reservoir contained gas and water. The low impedance and low density characteristics have been showed in both of gas layer and water layer, but the acoustic impedance and density of gas layer is lower than water layer, which caused that the impedance difference between gas layer and the overlying mudstone is far greater than the difference between aquifer and mudstone. There is a close relationship between the difference of $\mathrm{P}$-wave impedance and the reflection coefficient, which is that the impedance difference is big, the reflection coefficient is large, and the impedance difference is small, the reflection coefficient is small. The value of the reflection coefficient determines the amplitude value of the seismic profile. Therefore, gas layer and water layer will show different amplitude values in the seismic profile. In this case, whether gas layer and water layer can be identified directly on the seismic profile by analyzing the amplitude of bright spot, so as to reduce the multi-solution of bright spot identification [10] [11] [12] [13]? Based on rock physics analysis and using the current amplitude fidelity of seismic data, the quantitative interpretation research of bright spot has been carried out from the perspective of amplitude quantification for gas layer and water layer, which directed the identification of hydrocarbon reservoir in study area and laid the foundation for the success of subsequent wells.

\section{Principle of Method}

In order to realize the purpose of explaining the bright spot directly into gas layer or water layer in seismic profile, first of all, based on the petrophysical analysis for the wells drilled and according to the relationship between the impedance of the reservoir and the surrounding rock, determine the relative relationship of amplitude between the reservoir and the surrounding rock by using simulation method, combine the relationship with the statistical results of the actual seismic amplitude value corresponding to the drilled reservoir, distinguish bright spots shown by gas layer and water layer with the quantitative display means, eliminate the false bright spots caused by water layer and highlight the true bright spots caused by gas layer [14] [15] [16].

Then, based on the above understanding and aimed at the different situation of reservoir contained gas and water, carry out the petrophysical analysis deeply, find the sensitive elastic parameters of gas layer and water layer, conduct the forward modeling of reservoir fluid, physical properties and thickness tuning by using wedge model, further simulate and analyze the relationship of amplitude value caused by the impedance difference between gas layer, water layer and surrounding rock, determine the numerical value of gas layer and water layer amplitude under the same surrounding rock.

Ultimately, combined with the actual seismic amplitude statistics of gas layer 
and water layer in wells drilled, establish the quantitative relationship between reservoir and amplitude [17], form a quantitative interpretation and evaluation technique for Huangliu Formation reservoirs in the central canyon.

\subsection{Analysis of Seismic Rock Physics}

Based on the petrophysical analysis of the well drilled in the study area (Figure 2), we know that the gas group in the well L1 shows the significant characteristics of low impedance and low density compared with the overlaying rock (mudstone), meanwhile, which still presents the feature of low impedance and low density compared with the lower water layer (sandstone). However, the $\mathrm{P}$-wave impedance difference between gas layer and water layer is smaller than that between gas layer and mudstone.

The analysis results of Huangliu Formation in other two wells indicate that gas layer still displays the characteristics of low impedance and low den-
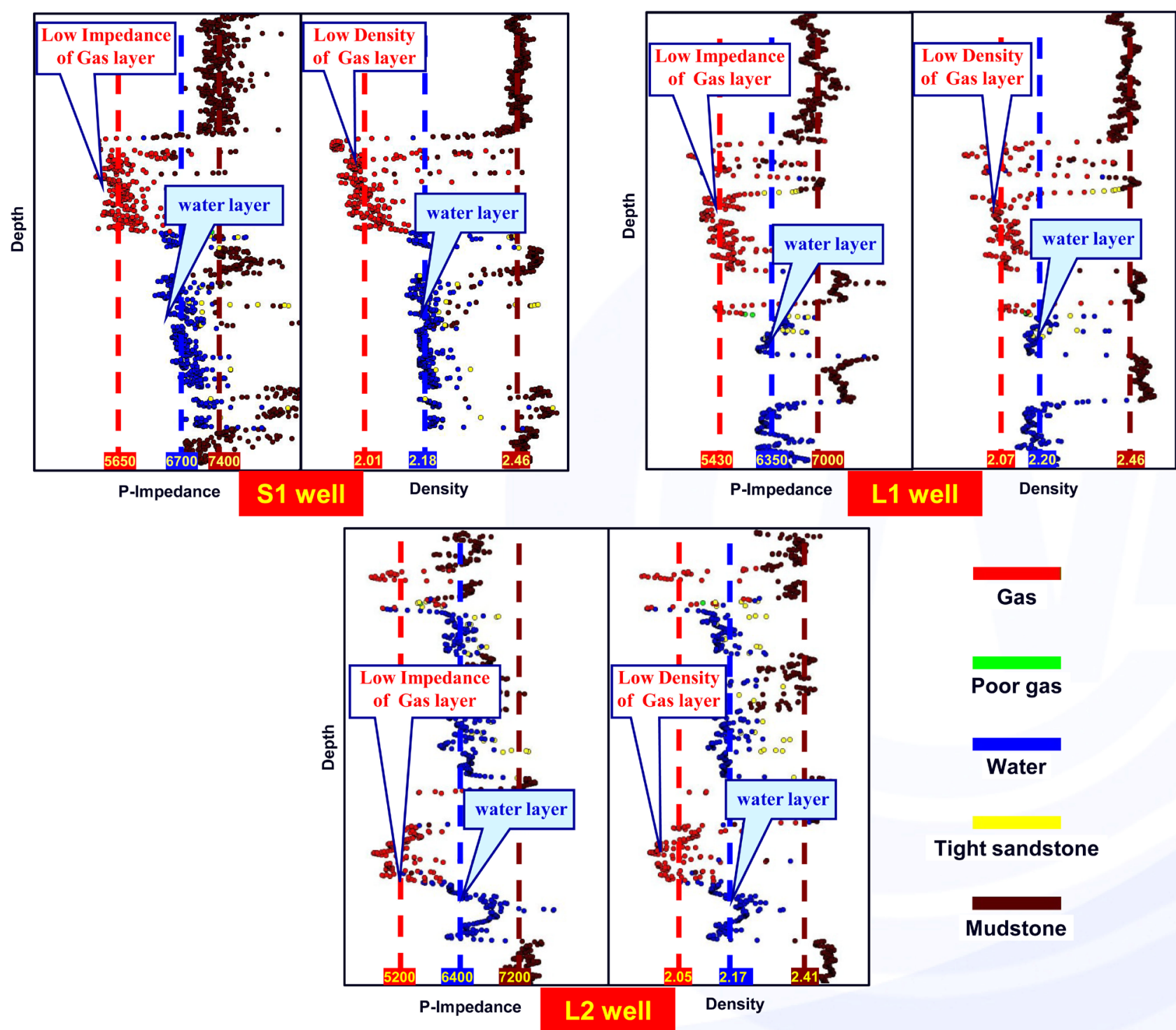

Tight sandstone

Figure 2. The petrophysical analysis of the well drilled in the Central Canyon. 
sity, and the P-wave impedance difference between water layer and mudstone is much smaller than that of gas layer and mudstone. Therefore, the petrophysical analysis results of three wells give that once the reservoir is filled with gas, the impedance of it will be far less than that of water layer, and there is obvious difference between these layers of Huangliu Formation with the density of mudstone, water layer and gas layer decreasing.

\subsection{Forward Modeling of Amplitude of Reservoir}

The principle of seismic exploration tells that the amplitude value of the interface between the underground geological bodies is proportional to the reflection coefficient size of it and there is the following relationship between the reflection coefficient size and the impedance value of upper and lower media [18].

$$
R_{P}=\frac{\rho_{2} V_{2}-\rho_{1} V_{1}}{\rho_{2} V_{2}+\rho_{1} V_{1}}
$$

Here, $R_{P}$ is reflection coefficient, $\rho_{1} V_{1}$ is P-wave impedance of overlaying rock, $\rho_{2} V_{2}$ is $\mathrm{P}$-wave impedance of underlying rock.

Known from the above describing, there is a numerical relationship between the seismic amplitude and the reservoir. However, what is this relationship? It needs to be ascertained by forward modeling. Previous studies [19] [20] indicated that the seismic amplitude is mainly affected by the following three factors: acquisition, processing and geological reasons which include the reflection coefficient, the thickness tuning, multi-layer interference, etc. It is considered that the influence factors of the seismic amplitude is mainly due to the geological factors such as the difference of the reflection coefficient caused by the difference of the fluid and the physical property, the thickness tuning caused by the thickness variation, etc. Because multilayer interference as the influence factors of the thickness can increase the complexity of seismic amplitude, only the physical property difference, the change of the fluid and the thickness tuning will be considered as the main influence factors of seismic amplitude in this study, but not the multilayer interference. Based on the petrophysical characteristics of the reservoir and the influence factors of the amplitude, the forward modeling is studied from three aspects.

\section{1) Physical property}

According to the physical property data of the reservoir of the wells drilled, designed porosity within the range from $23 \%$ to $30 \%$, conducted forward modeling of gas layer and water layer for each value of the porosity, got the statistics for each simulation results (Figure 3), obtained the relationship with porosity changes between the reservoir (including gas layer and water layer) and amplitude (Figure 4). In Figure 4, the Red color indicates the maximum tuning amplitude of gas layer, the Magenta color indicates the non-tuning amplitude of gas layer, the Blue color presents the maximum tuning amplitude of water layer and the Purple color presents the non-tuning amplitude of water layer. As can be seen from Figure 4, i) with the increase of porosity, the amplitude of gas layer and water layer increases gradually; ii) under the same porosity, the maximum 

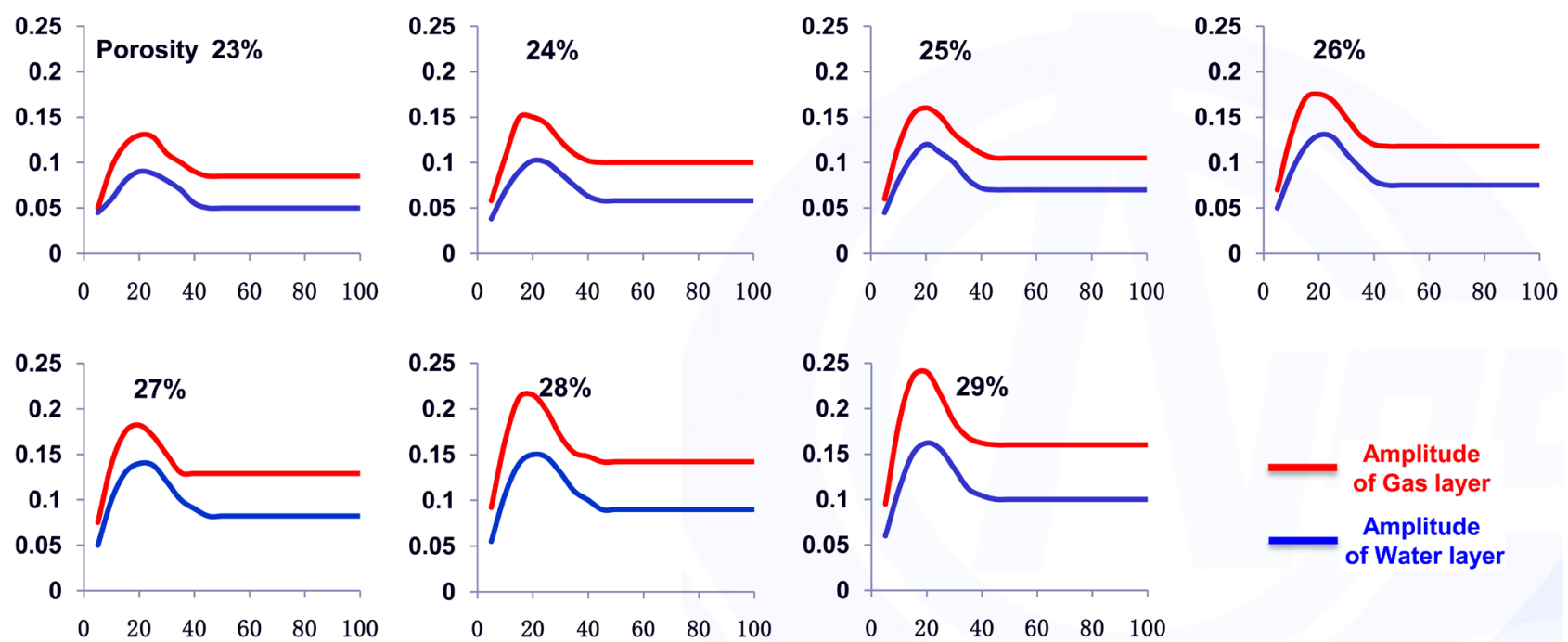

Figure 3. The physical property, the thickness and the amplitude relationship analysis.

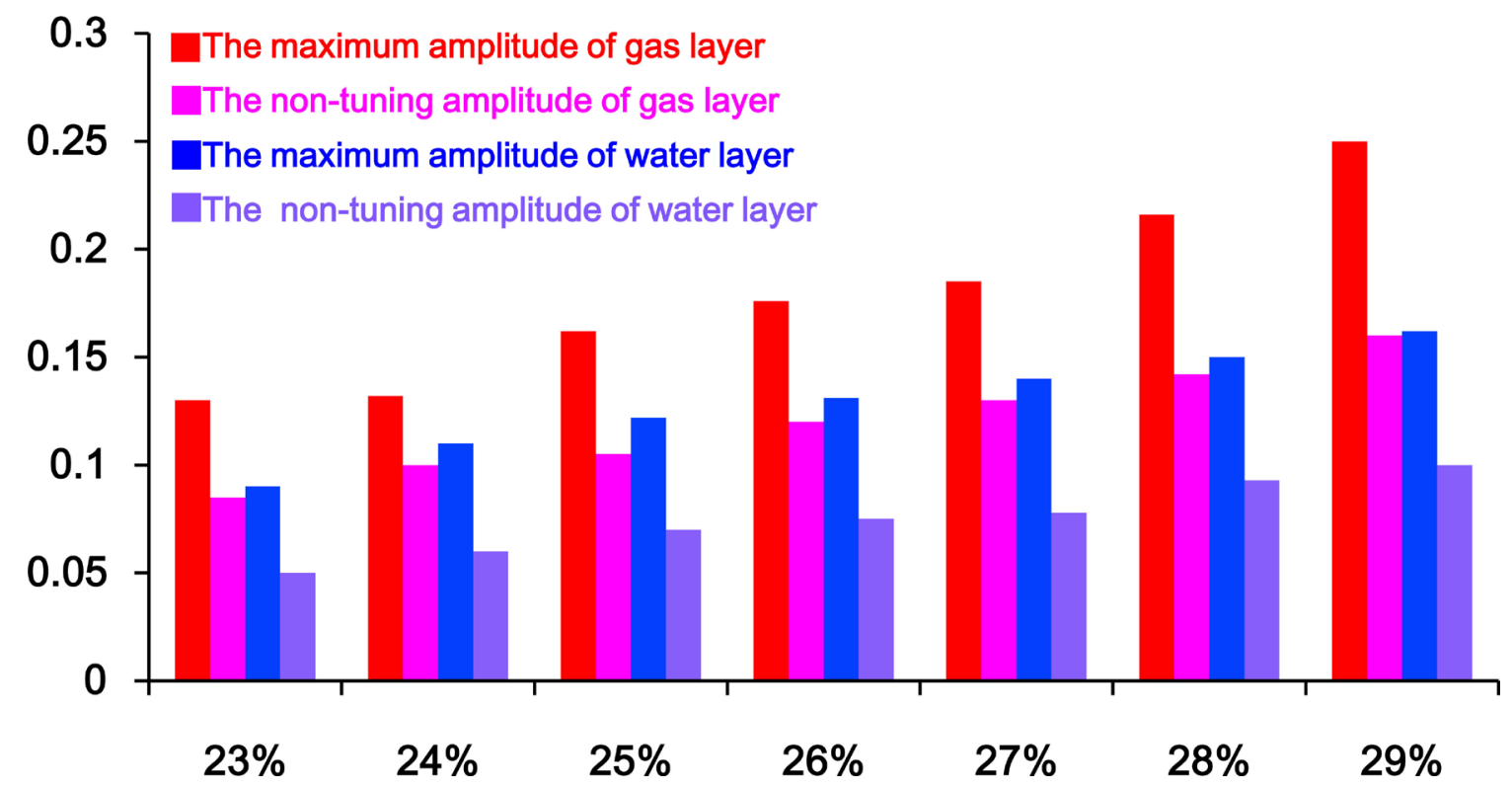

Figure 4. The amplitude relationship analysis of gas layer and water layer in different porosity.

tuning amplitude of gas layer is greater than that of other three layers, the maximum tuning amplitude of water layer is equivalent to that of gas layer, and it is less than the maximum tuning amplitude of gas layer, the non-tuning amplitude of water layer is smallest; iii) When the difference between two different porosities is in the range of $3 \%$ to $4 \%$, the non-tuning amplitude of gas layer with small porosity is still greater than the non-tuning amplitude of water layer with large porosity.

\section{2) Fluid}

The reservoir drilled in Huangliu Formation are mainly explained as gas layer and water layer, so gas layer and water layer with different depths were chosen in three wells drilled respectively, and the amplitude of these layers was simulated. It is known from the simulation results (Figure 5) that the amplitude of gas 


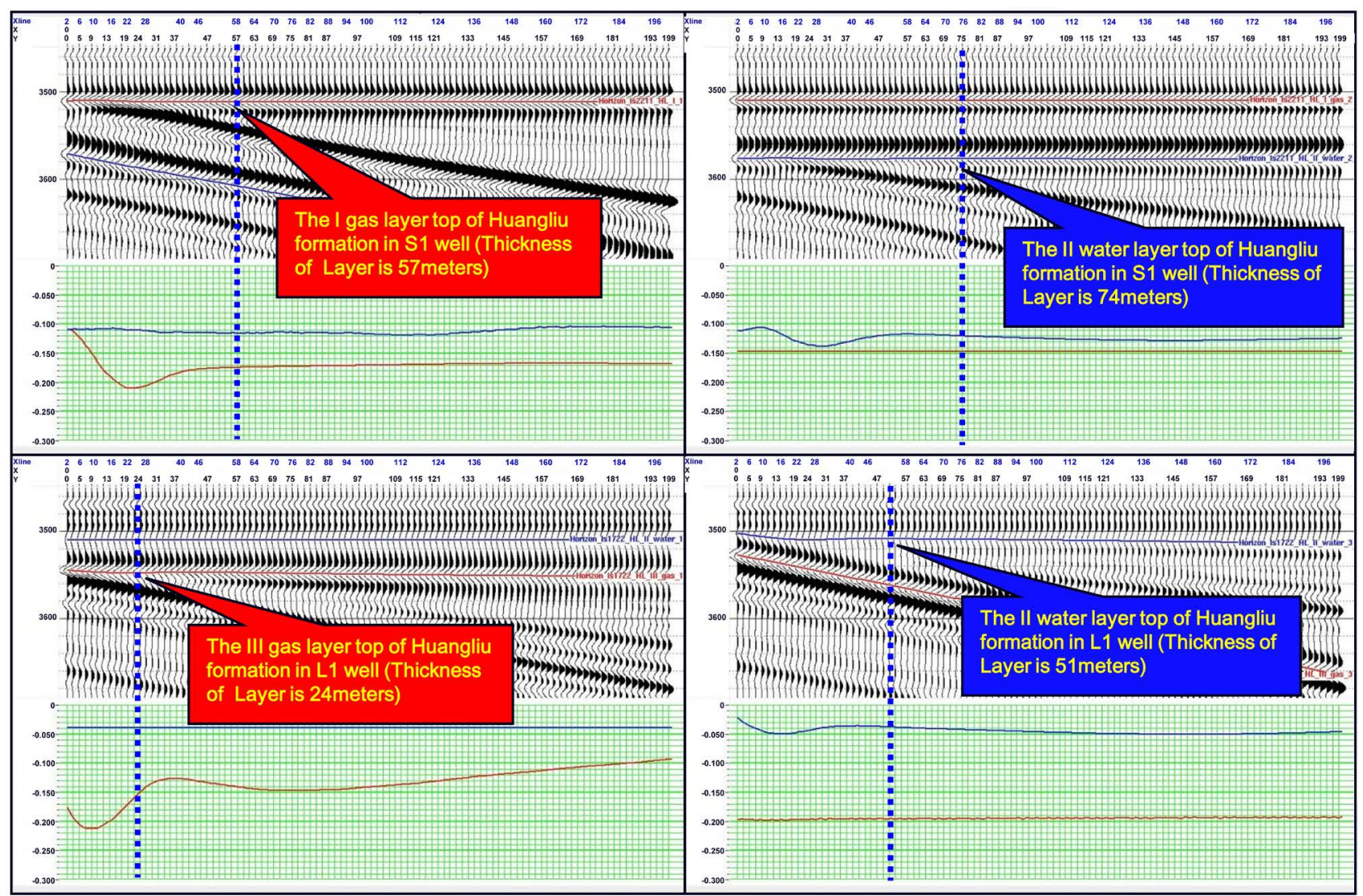

Figure 5. The forward modeling of gas layer and water layer in the central canyon.

layer is much larger than that of water layer, which is consistent with the amplitude value of gas layer and water layer extracted from the seismic profile. These results show that the top surface of gas layer can lead to stronger seismic amplitude, and there is a great difference of amplitude caused by the top surface of gas layer and that of water layer in the seismic profile, which can be distinguished by naked eyes.

\section{3) Thickness tuning}

The corresponding wedge models have been designed respectively for gas layer and water layer chosen above, meanwhile, the forward modeling of the effect of thickness tuning on amplitude has been carried out for these layers. The steps of simulation are as follows: firstly, according to the actual logging data, the corresponding velocity and density curves of gas layer and water layer have been turned into square wave; secondly, referring to the thickness of the sand which has been drilled, the thickness of the wedge model is changed from $0 \mathrm{~m}$ to 2 times the maximum thickness of reservoir; finally, the wedge model has been simulated by using theoretical wavelet(Ricker) and the wavelet extracted from Well-to-Seismic Calibration referring to convolution theory. The frequency of Ricker wavelet is determined in the light of the main frequency of the objective layer obtained from frequency analysis of the seismic data.

The simulation result shows that the amplitude values of gas layer and water layer have increased with the increasing of thickness gradually, when the thick- 
ness increases to a certain value, the amplitudes of gas layer and water layer reach the maximum value (the maximum tuning amplitude), then the amplitude with thickness decreases, at last, the amplitude tends to be stable after the thickness reaches a certain greater value. As a whole, the amplitude of gas layer is stronger than that of water layer, even if water layer is in the maximum tuning amplitude, the value of which is still smaller than that of gas layer (Figure 6). Further analyzing the relationship between the amplitude values of gas layer and water layer deeply, pick up the maximum tuning amplitude value of gas layer, the non-tuning amplitude value of gas layer, the maximum tuning amplitude value of water layer and the non-tuning amplitude value of water layer, think that there are multiple relationship between the amplitude values of gas layer and water layer like this: $1.1 \sim 2.6$ after comparing and calculating the four kinds of data (Figure 7). In addition, when the gas layer and water layer in the study area get the maximum tuning amplitude, the corresponding thickness is $16 \mathrm{~m}$ and $19 \mathrm{~m}$ respectively; when the amplitude of gas layer and water layer is transferred from tuning to non-tuning, the thickness of them is $32 \mathrm{~m}$ and $38 \mathrm{~m}$ respectively; both of the amplitudes tend to be stable and remain unchanged when the thickness of them is more than $32 \mathrm{~m}$ and $38 \mathrm{~m}$ respectively.

The thickness tuning forward modeling of the theoretical model of the Huangliu formation I gas layer in S1 well

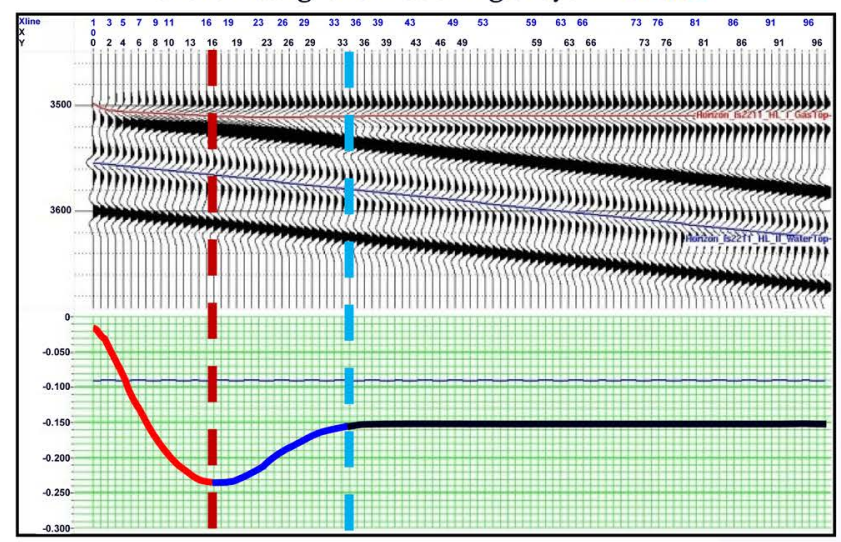

The thickness tuning forward modeling of the theoretical model of the Huangliu formation $\mathrm{I}_{\text {down }}$ gas layer in L1 well

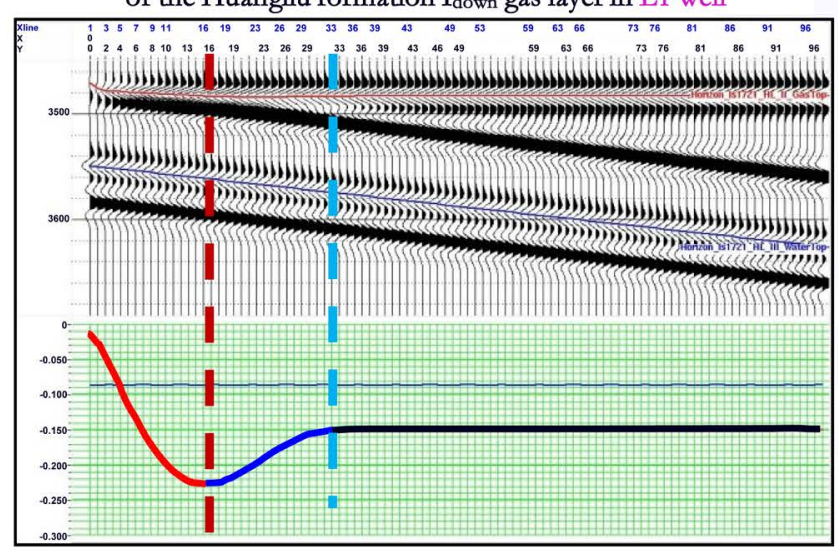

The thickness tuning forward modeling of the theoretical model of the Huangliu formation II water layer in S1 well

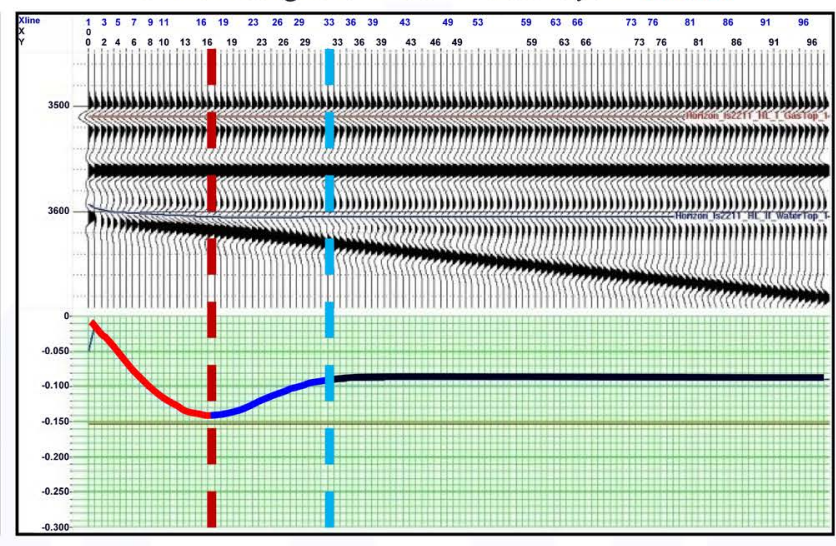

The thickness tuning forward modeling of the theoretical model of the Huangliu formation III water layer in L1 well

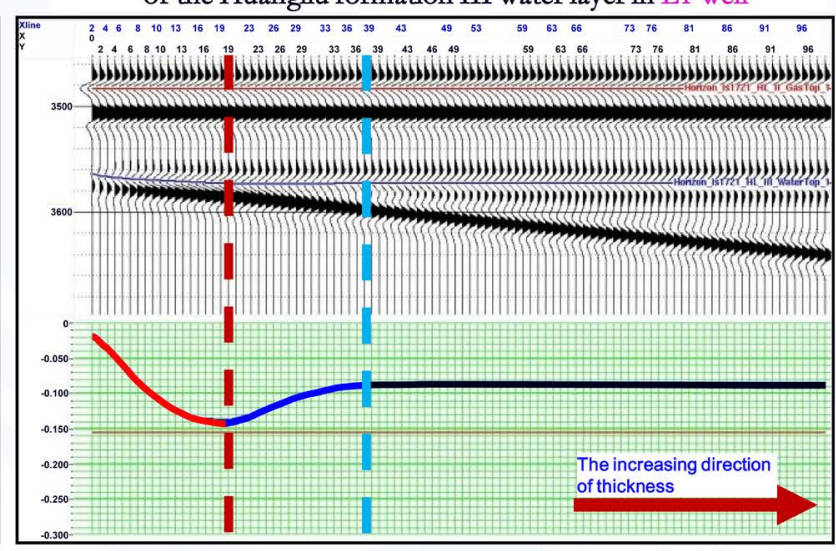

Note: using Riker wavelet

Figure 6. The influence analysis of the reservoir amplitudes during the thickness tuning. 


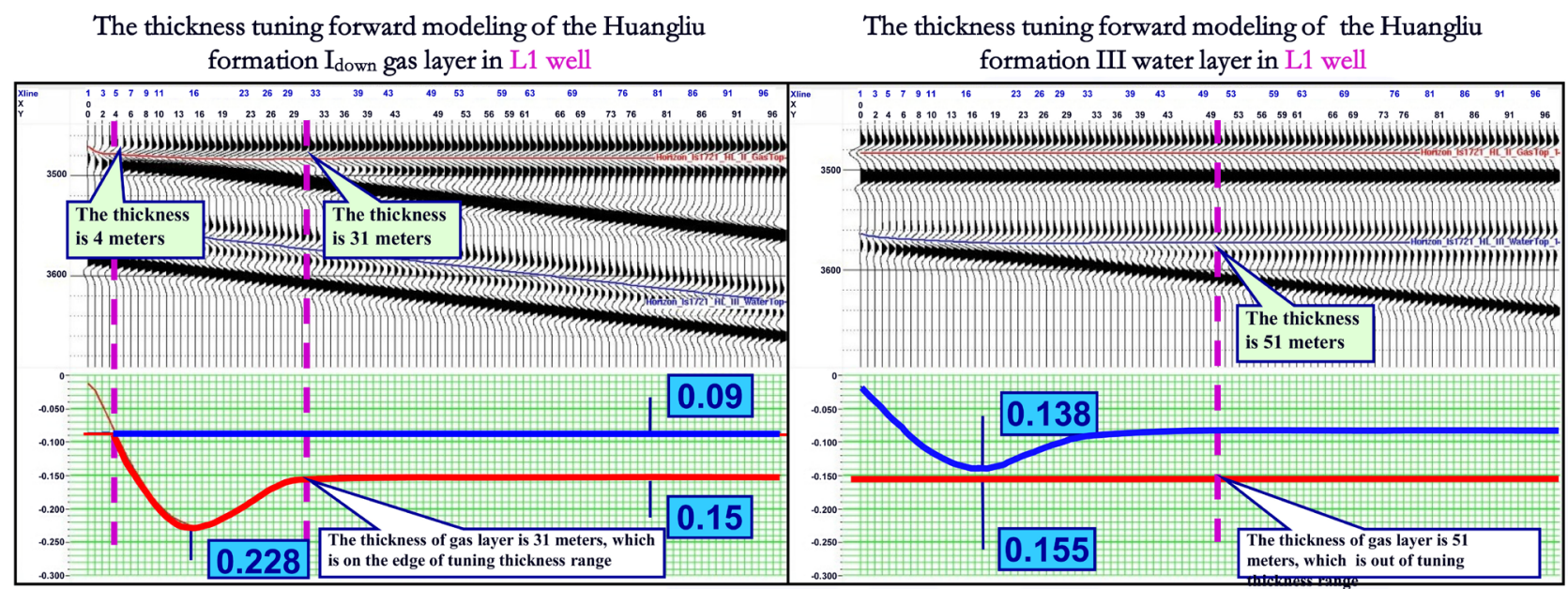

Figure 7. The numerical relationship analysis of gas layer and water layer.

\subsection{Bright Spot Quantitative Interpretation and Evaluation}

After determining the numerical relationship between the amplitudes of different reservoirs, according to the amplitude threshold values of gas layer and water layer, eliminate the false bright spots caused by water layer on the seismic profile, retain the true bright spots of gas layer, finally, identify the real highlights of gas layer quickly and accurately.

1) The amplitude statistics of actual reservoir drilled

It is necessary to achieve the amplitude statistics of seismic trace near wells drilled corresponding to the reservoir drilled before determining the gain parameters. After the well-seismic calibration done, each reservoir is corresponded to the event in seismic profile one by one, and then the seismic amplitude value corresponding to each reservoir is picked up. The amplitude statistics of gas layer and water layer of three wells drilled in this study are as follows (Table 1), which has been obtained by the method above.

Combined with the multiple relations between the maximum tuning amplitude or the non-tuning amplitude of gas layer and that of water layer on the basis of forward modeling analysis as mentioned in the article, the range of the amplitude of water layer is calculated, then after comprehensive considered, the threshold used to remove the bright spots caused by water layer will be confirmed.

\section{2) Confirming the thresholds of gas layer and water layer}

The multiple relation between the amplitude value of gas layer and that of water layer is as follows: $1.1 \sim 2.6$ from the forward modeling, which shows that the absolute value of the amplitude of gas layer is still greater than that of water layer even if the amplitude of water layer is the maximum tuning amplitude and that of gas layer is the non-tuning amplitude. It is known that the average amplitude of water layer is about $-0.35 \mathrm{e}+08$ from the statistical data of the actual amplitude of the wells drilled, therefore, combined with the results of forward modeling and the amplitude statistics of the reservoir, the threshold value of water layer can be set to $-0.35 e+08$. Next, the amplitude values of the event are 
weakened by reducing the gain of seismic profile, which is greater than the threshold of water layer, and the event that still shows very strong amplitude in the profile is the top interface of gas layer (Figure 8).

Table 1. The amplitudes and the porosity statistics of the well drilled in the central canyon.

\begin{tabular}{|c|c|c|c|c|c|c|}
\hline $\begin{array}{l}\text { Well } \\
\text { name }\end{array}$ & Sand & $\begin{array}{l}\text { Amplitude } \\
\text { in well }\end{array}$ & $\begin{array}{l}\text { Amplitude average } \\
\text { around well }\end{array}$ & $\begin{array}{l}\text { Thickness } \\
\text { in well }(\mathrm{m})\end{array}$ & $\begin{array}{c}\text { Porosity } \\
\text { in well (\%) }\end{array}$ & Note \\
\hline \multirow{2}{*}{ S1 } & I & $-5.02 \times 10^{8}$ & $-5.3 \times 10^{8}$ & 58.4 & 27.49 & gas \\
\hline & II & $-4.05 \times 10^{8}$ & $-3 \times 10^{8}$ & 68.2 & 30.18 & water \\
\hline \multirow{5}{*}{ L1 } & $\mathrm{I}_{\mathrm{up}}$ & $-7.2 \times 10^{8}$ & $-8.1 \times 10^{8}$ & 12 & 28.8 & gas \\
\hline & $\mathrm{I}_{\text {down }}$ & $-5.2 \times 10^{8}$ & $-7.2 \times 10^{8}$ & 30.9 & 27.49 & gas \\
\hline & II & $-3.85 \times 10^{8}$ & $-5.1 \times 10^{8}$ & 4.3 & 27.85 & gas \\
\hline & III & $-3.27 \times 10^{8}$ & $-3.0 \times 10^{8}$ & 62 & 25.02 & water \\
\hline & IV & $-6.75 \times 10^{8}$ & $-4.15 \times 10^{8}$ & 6.2 & 23.98 & gas \\
\hline \multirow{4}{*}{$\mathrm{L} 2$} & I & $-6.0 \times 10^{8}$ & $-5.9 \times 10^{8}$ & 7.4 & 27.1 & gas \\
\hline & II & $-2.0 \times 10^{8}$ & $-2.4 \times 10^{8}$ & 26.3 & 25.72 & water \\
\hline & III & $-10.2 \times 10^{8}$ & $-8.5 \times 10^{8}$ & 22.1 & 27.73 & gas \\
\hline & IV & $-4.5 \times 10^{8}$ & $-4.0 \times 10^{8}$ & 12.2 & 28.62 & Water (gas contained in top of layer) \\
\hline
\end{tabular}

The amplitude values which is less than $-3 e+8$ are all indicated by black color completely.
The amplitude values which is less than $-9 e+8$ are all indicated by black color completely now.

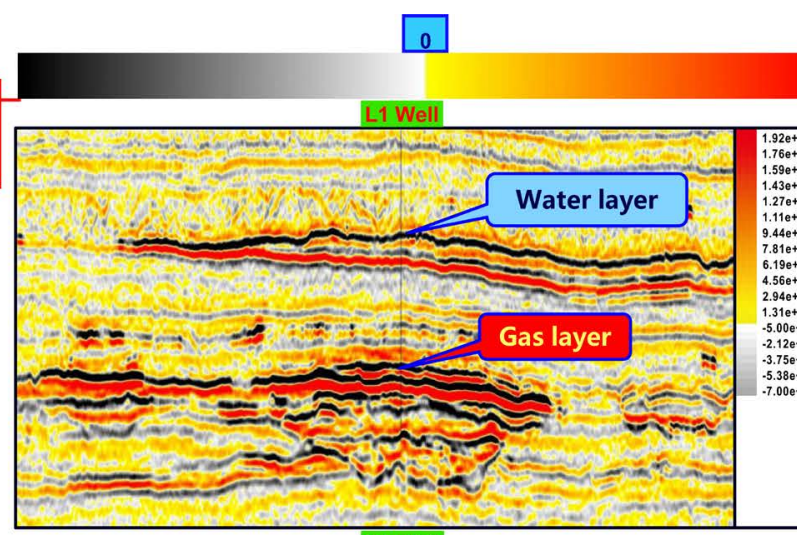

L1 Well

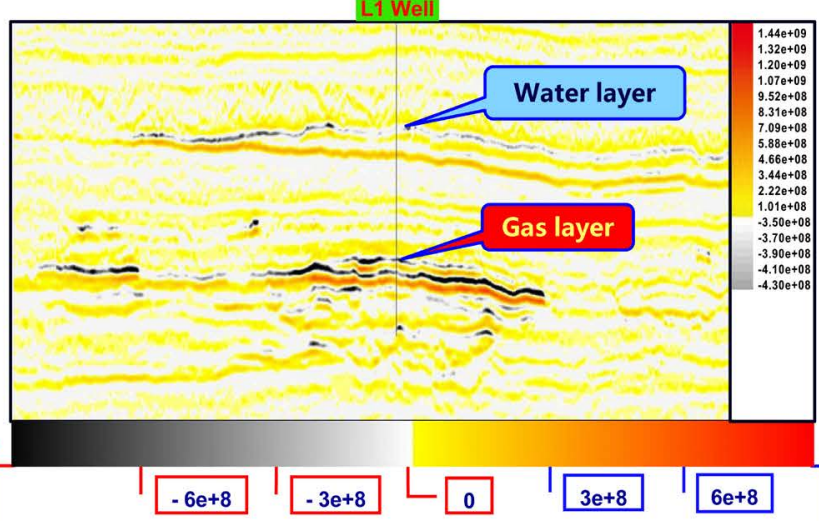

The amplitude values which is greater than $3 e+8$ are all indicated by red color completely.

Figure 8. The quantitative visualization of the amplitudes for seismic section. 


\section{Application Effect Analysis in Practice}

According to the petrophysical analysis and study on regional geological conditions, studied the quantitative relationship between the reservoir and the amplitude by the forward modeling; formed the quantitative interpretation evaluation technology of Bright Spot; identified the real bright spot; then, by using the technique combined with pre-stack joint inversion, judged the gas bearing of bright spot in the undrilled structure of Huangliu formation of the Central Canyon; finally, proved the gas-bearing prediction accuracy by practical drilling.

\subsection{Application of Gas Bearing Prediction}

In this paper, the quantitative analysis of bright spot and the gas bearing prediction of it are carried out by using the technique of bright spot and pre-stack joint inversion before drilling well L3/L4 (Figure 9). It can be seen from the cross section of two wells in Figure 9 that the seismic amplitude of each gas group at the well L4 point has been preserved after the treatment of amplitude quantitative weakening, which is still showing strong energy. At the same time, the I and IV gas groups in the Huangliu formation of the well L3 point show strong amplitude energy. However, the II and III gas groups present weak amplitude. According to the principle of quantitative interpretation of the bright spot, it is considered that each of these gas groups with strong amplitude feature in the two wells is the true bright spot.

On the basis of fine description of sand body, pre-stack joint inversion is carried out by pre-stack seismic data with interpretative processing. It can be shown (Figure 10) that each of these gas groups distinguished corresponds to remarkable low P-wave impedance and low density anomaly. Combined with the results of rock physics analysis, it is thought that there is a great possibility of gas bearing in these gas groups mentioned above. After drilling, logging interpretation shows that the I, II, III and IV gas groups of Huangliu formation in the well L4 are all high productive gas layers, the I and IV gas groups of Huangliu formation in the well L3 are also high productive gas layers, however, the II and III gas groups are all water layers. The result of log interpretation is completely consistent to the prediction before drilling. Furthermore, high industrial gas-flow is obtained from these gas groups of two wells after gas testing.

Similarly, the above techniques are used in the section through well L8. It is predicted that the I gas group of Huangliu formation in well L8 have been filled with gas, and the II gas group of Huangliu formation in well L8 has been filled without gas (Figure 11). After drilling, the log interpretation results are consistent with the prediction. High industrial gas-flow is also obtained from the well.

\subsection{Application Prospection}

In addition to being able to distinguish the true and false bright spots in the seismic profile, the quantitative interpretation of bright spot can be used to guide the coring test, well completion and drilling target selection in the drilling process. Practice has proved that the application of this technology in the recog- 
nition of gas layer and water layer and in drilling operations has achieved good results. It is not only presented that the method is simple and practical and it

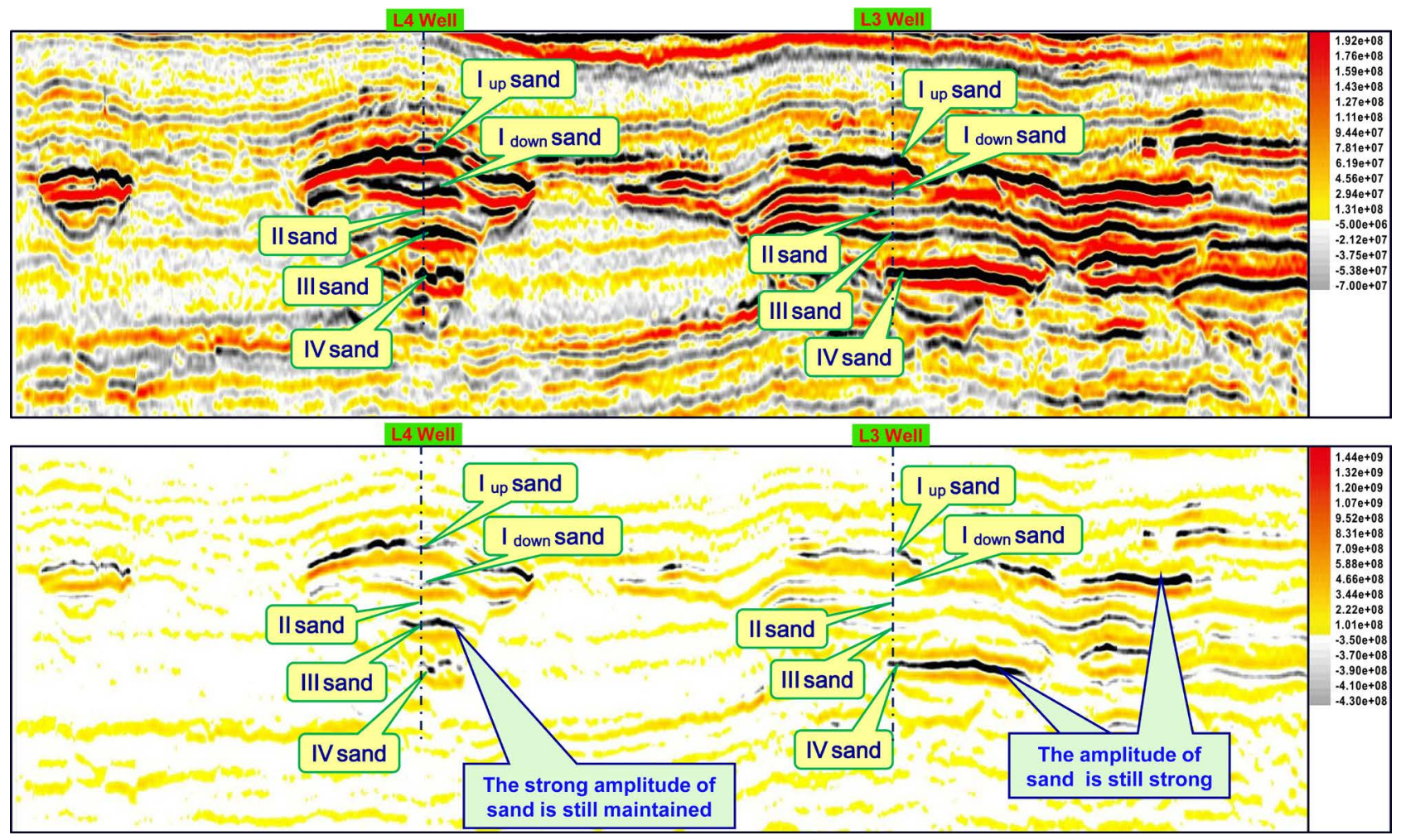

Figure 9. The amplitude quantitative interpretation of well L3 and L4 before drilling.

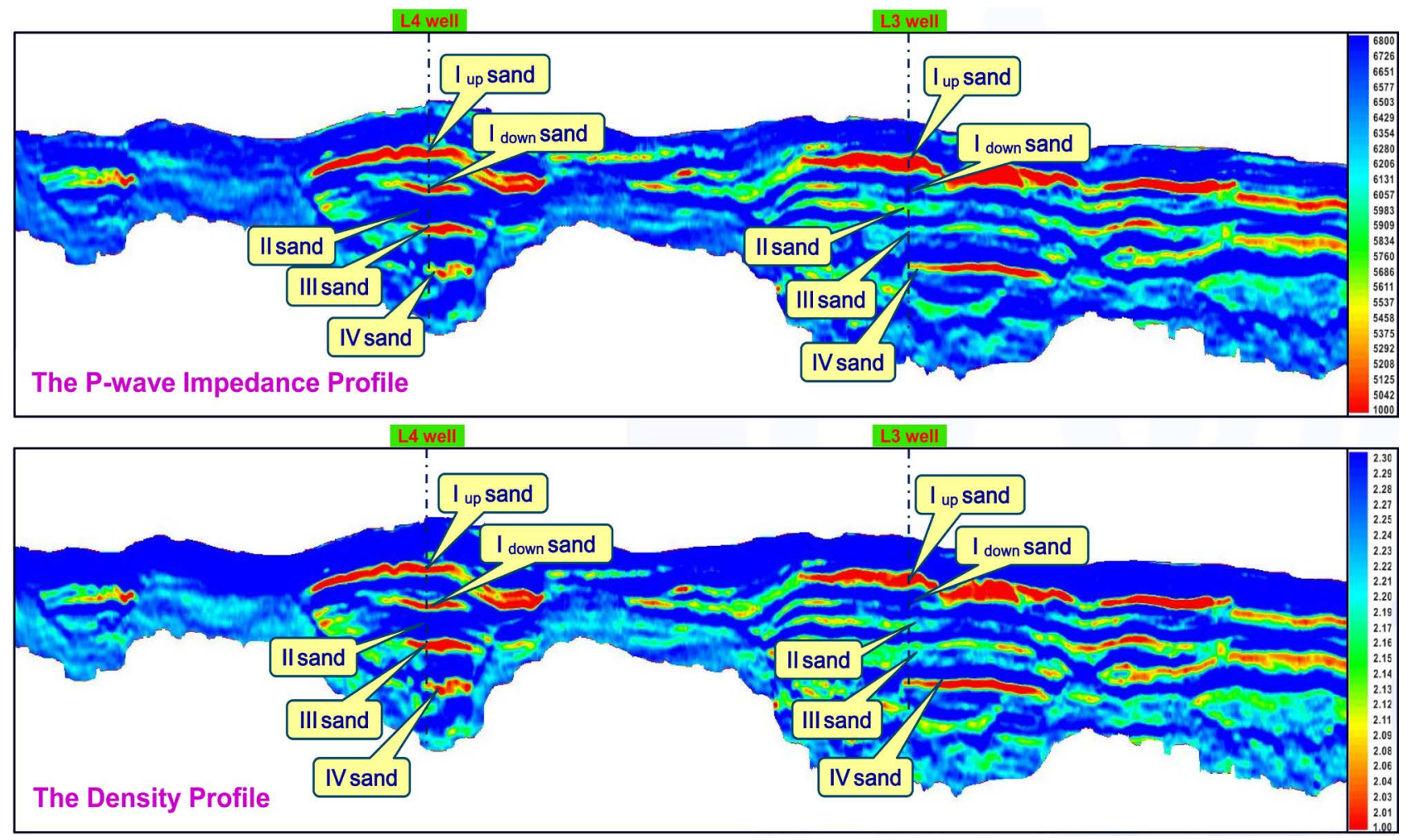

Figure 10. The pre-stack inversion of the section through well L3 and L4 before drilling. 

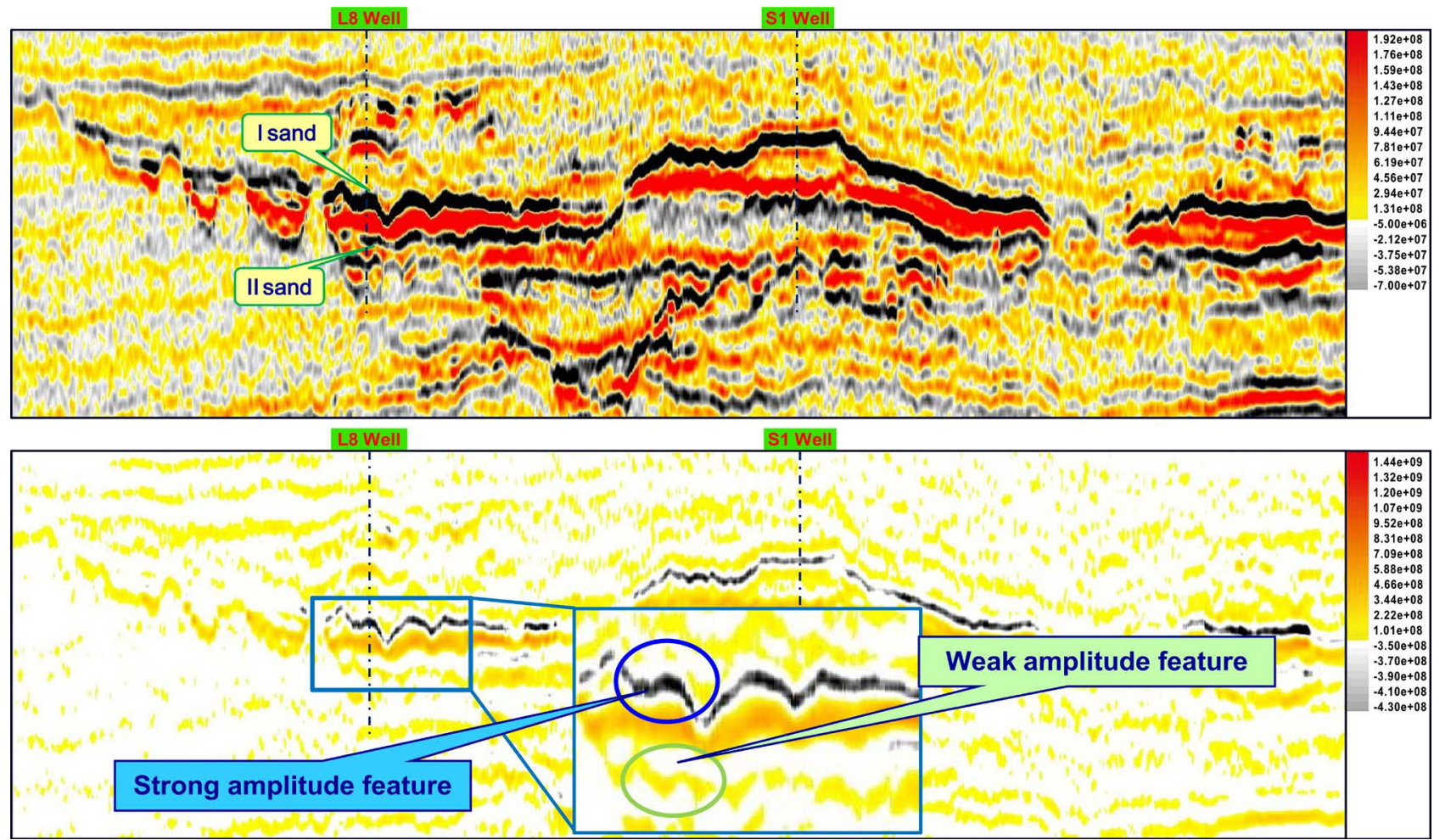

Figure 11. The amplitude quantitative interpretation of well L8 before drilling.

plays an important role in the objective assessment, but also that its application brings direct economic benefits for production operations, especially the increase of reserves, saving the drilling cost.

\section{Conclusions and Suggestion}

Through the quantitative analysis and case study, we can draw the following conclusions.

For a certain depth and porosity, whether the reservoir thickness is tuned or not, seismic amplitude of gas layer showed stronger than that of water layer in seismic profile, which established theory foundation of identifying "true" and "false" bright spots in the seismic section.

Application effect of exploration example demonstrates that this method of amplitude quantitative identification has strong practicability and robustness, which has provided a new idea for distinguishing true and false bright spots and reduced the risk of oil and gas exploration to some extent.

However, there are still some limitations in the quantitative identification of bright spot, which does not take into account the influence of reservoir buried depth on seismic amplitude. In the future, we will study the reservoir amplitude combined with the diagenesis.

\section{Fund Project}

National Science and technology major special projects supported by 2016ZX05026-002. 


\section{References}

[1] Fu, C.F. (1975) "Bright Spot" Technology-The Method of Directly Searching Oil and Gas by Using Seismic Profile. Oil Geophysical Prospecting, 10, 9-34.

[2] Calculating Station of Chengdu Institute of Geology, et al. (1977) "Bright Spot" Model Technique. Geophysical Prospecting for Petroleum, 4, 46-53, 55-62.

[3] Wang, L.Q. (1984) The Bright Spot in Traditional Seismic Profile. Oil Geophysical Prospecting, 19, 80-86.

[4] Wang, D.C. (1982) The Detection Effect of Bright Spot in Continental Facies Strata. Oil Geophysical Prospecting, 17, 30-35.

[5] The Intelligence Department of Geophysical Prospecting Bureau of China Petroleum (1975) The Warning of Bright Spot-There Is Not Really without Mistake. Oil Geophysical Prospecting, 2, 40-41.

[6] Almoghrabi, H., et al. (1986) Layers \& Bright Spots. Geophysics, 51, 699-709. https://doi.org/10.1190/1.1442123

[7] Pan, Y.J. (1988) The Relationship between Bright Spot, Dark Spot and Oil-Gas. Oil Geophysical Prospecting, 6, 737-744.

[8] He, Z.H. and Ma, C.D. (1989) The Feasibility of Finding Gas by "Bright Spot" in Junggar Basin, Xinjiang Petroleum. Geology, 10, 14-23.

[9] Yang, Y.L., Sun, H.F. and Wang, H.Z. (1991) The Research on Bright Spot and Its Application of Shallow Gas Exploration in the Dongying Sag. Geophysical Prospecting for Petroleum, 1, 39-49.

[10] Wang, Y.J. and Wang, X.M. (1995) The Feature and the Recognition of Bright Spot Gas Reservoir in the 3-D Seismic Data of Jiyang Depression. Geophysical Prospecting for Petroleum, 4, 66-72.

[11] Wei, W., Li, H.M., Yang, Y.L., et al. (2011) The Recognition Technique of True and False Bright Spot in the Shallow of Chenjiazhuang Area. Reservoir Evaluation and Development, 1, 12-15.

[12] Zhao, S. and Gao, Q. (2013) Using Adjacent Seismic Reflection Characteristics of the Energy Mix to Exclude "Bright Spot" Trap-Taking Deyang Syncline in Western Sichuan Depression as an Example. Natural Gas Geoscience, 24, 1253-1259.

[13] Liu, W. and Cao, S.Y. (2015) Identification of Gas Reservoir Related with Bright Spots and Thin-Bed Tuning. Oil Geophysical Prospecting, 50, 678-683, 705.

[14] Zhu, H.T., Hu, X.Q. and Chen, X.J. (2002) Preliminary Study on the Application of Bright Spots Oil and Gas Testing Technique. Offshore Oil, 3, 27-32.

[15] Li, S.E., Zhang, Y.Z. and Wen, Y.J. (2003) Shallow Formation Bright Spot and Gas Exploration. Natural Gas Geoscience, 14, 291-294.

[16] Cai, X.B. (2012) The Effectiveness Analysis of Using "Bright Spot”, "Dark Spot” Technique to Test Oil and Gas in Putaohua Reservoir of Taipingchuan Region. Science Technology and Engineering, 12, 2132-2136.

[17] Xiao, Z.B., Zhang, J.M. and Cao, X.Y. (2013) The Application Analysis of Bright Spot Technology Based on the Statistics of the Physical Rock. Computerized Tomography Theory and Applications, 22, 447-454.

[18] Lu, J.M. (1993) Principle of Seismic Exploration. Petroleum Industry Press, Beijing, 19-20.

[19] Jiang, B.H., Cai, Y.Q. and Wang, Y.Y. (2012) Analysis of Influence Factors on Seismic Amplitude in Bohai Sea Area. Petroleum Geology and Engineering, 26, 47-51.

[20] Zhou, J.X., Liu, W.W. and Ma, G.K. (2013) Fine Description and Prediction of Seismic Attributes of HPHT Gas Reservoirs in the Yinggehai Basin. Natural Gas Industry, 33, 7-11. 
Submit or recommend next manuscript to SCIRP and we will provide best service for you:

Accepting pre-submission inquiries through Email, Facebook, LinkedIn, Twitter, etc. A wide selection of journals (inclusive of 9 subjects, more than 200 journals)

Providing 24-hour high-quality service

User-friendly online submission system

Fair and swift peer-review system

Efficient typesetting and proofreading procedure

Display of the result of downloads and visits, as well as the number of cited articles Maximum dissemination of your research work

Submit your manuscript at: http://papersubmission.scirp.org/

Or contact ojg@scirp.org 